\begin{tabular}{|c|l|}
\hline Title & Mesoporous smectites incorporated with alkali metal cations as solid base catalysts \\
\hline Author(s) & Fujita, Shin-Ichiro; Bhanage, Bhalchandra M.; A oki, Daishi; Ochiai, Y uri; I wasa, Nobuhiro; A rai, Masahiko \\
\hline Citation & $\begin{array}{l}\text { A pplied Catalysis A General, 313(2), 151-159 } \\
\text { https://doi.org/10.1016/.apcata.2006.07.018 }\end{array}$ \\
\hline Issue Date & $2006-10$-04 \\
\hline Doc URL & http://hdl.handle.net/2115/14888 \\
\hline Type & article (author version) \\
\hline File Information & ACA-G313-2.pdf \\
\hline
\end{tabular}

Instructions for use 


\title{
Mesoporous smectites incorporated with alkaline metal cations as solid base catalysts
}

Shin-ichiro Fujita, ${ }^{\mathrm{a}}$ Bhalchandra M. Bhanage, ${ }^{\mathrm{a}, \mathrm{b}}$ Daishi Aoki, ${ }^{\mathrm{a}}$ Yuri Ochiai, ${ }^{\mathrm{a}}$ Nobuhiro Iwasa, ${ }^{\mathrm{a}}$ Masahiko Arai $^{\mathrm{a}}$

${ }^{a}$ Division of Chemical Process Engineering, Graduate School of Engineering, Hokkaido University, Sapporo 060-8628, Japan

${ }^{b}$ Applied Chemistry Department, Institute of Chemical Technology, Mumbai University, N. Parekh Road, Matunga, Mumbai 400019, India

\begin{abstract}
A series of magnesium containing mesoporous smectites incorporated with alkali hydroxide $(\mathrm{NaOH}$, $\mathrm{KOH}$ or $\mathrm{LiOH}$ ) has been prepared and employed for such base-catalyzed model reactions as transesterification of ethyl acetate with methanol, Knoevenagel condensation of benzaldehyde with ethyl cyanoacetate and one-pot synthesis of dimethyl carbonate (DMC) from propylene oxide, carbon dioxide and methanol. The effects of the quantity and kind of the incorporated alkali atoms on the catalytic properties of the smectites were investigated. Characterization of the smectites has shown that the incorporation of alkali atoms reduces their surface area and total pore volume but enhances the amount and strength of their basic sites. The product yield of the transesterification was increased with the content of alkali atoms incorporated. It has been suggested that the moderately basic sites are responsible for this reaction. The yield of the Knoevenagel reaction depends little on the alkali atom content. Increasing the content of alkali atoms causes the increase in the DMC yield of the one-pot synthesis and the decrease in the yield of methanolysis of propylene oxide, which is the side reaction of the one-pot synthesis. The incorporation of Li was less effective than $\mathrm{Na}$ and $\mathrm{K}$ for the one-pot reaction. The structures of basic sites over the alkali-incorporated smectites have been discussed.
\end{abstract}

Keywords: Mesoporous materials; Alkali metal hydroxide; Transesterification; C-C bond formation; Carbon dioxide; Chemical fixation. 


\section{Introduction}

In conventional base-catalyzed organic syntheses, homogeneous catalysts such as alkali alkoxides and organic amines are used. However, they have drawbacks in catalyst-product separation and regeneration. Solid base catalysts are inexpensive and are more easily separable and recyclable than the homogeneous catalysts [1-5]. Hence, the use of solid base catalysts is desirable from the viewpoints of economy and green chemistry and is currently gaining much attention. However, little effort has been given to the study of solid base catalysts in contrast to extensive study of solid acid catalysts [1-5].

Smectite is one of the layered clay minerals in which one layer consists of one octahedral sheet sandwiched by two tetrahedral sheets. The octahedral sheet contains divalent or trivalent cations such as $\mathrm{Mg}^{2+}$ and $\mathrm{Al}^{3+}$ surrounded by six oxygen atoms and the tetrahedral sheet contains $\mathrm{Si}^{4+}$ cations surrounded by four oxygen atoms. The tri-layers are negatively charged and are held together by electrostatic interaction with exchangeable cations in the interlayer region. Synthesized smectites are a new kind of mesoporous materials [6-10]. Compared with other mesoporous materials like MCM-41 [11] and FSM-16 [12,13], these smectite-type materials can have wide variations in the chemical composition and porosity depending on precursors and synthesis conditions. It is possible to introduce various divalent or trivalent metal cations such as $\mathrm{Mg}, \mathrm{Co}, \mathrm{Ni}, \mathrm{Zn}$ and $\mathrm{Al}$ into the octahedral sheet. This allows the acidic and basic properties of the smectites to be tunable. This flexible feature makes the synthesized smectites interesting catalysts to investigate. These smectite-like materials have proved to be efficient base and/or acid catalysts in several reactions [14-19] and to be catalyst supports that are superior to conventionally used ones like silica [16-21].

As the first step of the synthesis of smectites, precursor materials are prepared by mixing aqueous solutions of raw materials (water glass and divalent or trivalent metal salt). Then, the slurries of the precursors and water are treated hydrothermally. By adding alkali compounds into the slurry before the hydrothermal treatment, alkali atoms can be introduced into smectites [9,22]. Recently, we have found that the incorporation of alkali atoms into the smectites makes them good catalysts for a few base catalyzed reactions relevant to chemical fixation of carbon dioxide to organic carbonate compounds [23-25]. However, alkali-incorporated smectites have not been studied sufficiently so far. Only a few papers covering the influence of alkali incorporation on the rheological properties of smectites in aqueous 
suspensions [22,26] and on the pore structure [9] have been published.

In the present study, a series of magnesium containing smectites into which various amounts of alkali hydroxides were incorporated were prepared and used for a few base-catalyzed model reactions. The model reactions selected were transesterification of ethyl acetate with methanol, Knoevenagel condensation of benzaldehyde with ethyl cyanoacetate and one-pot synthesis of dimethyl carbonate (DMC) from propylene oxide, carbon dioxide and methanol (Scheme 1). The effects of the quantity and kind of the incorporated alkali atoms on the catalytic properties of the smectites were investigated. The reaction results were discussed in connection with the basic properties of the catalysts that were determined by temperature programmed desorption of adsorbed carbon dioxide.

Scheme 1

\section{Experimental}

\subsection{Synthesis of smectite catalysts}

Smectite catalysts were synthesized with a hydrothermal method in which water glass $\left(\mathrm{SiO}_{2} 28 \%\right.$, $\mathrm{Na}_{2} \mathrm{O}$ 9\%) was used as the starting material. Water glass (86 g) and sulfuric acid (1.7 mol) were dissolved in $400 \mathrm{~cm}^{3}$ of water. Magnesium chloride hydrate (61.6 g) was dissolved in $200 \mathrm{ml}$ of water and then this solution was added to the previous water glass solution under stirring. The resulting solution was added dropwise to $400 \mathrm{~cm}^{3}$ of a $2 \mathrm{M} \mathrm{NaOH}$ solution. Si-Mg precipitates that formed was separated by filtration and washed with water. A slurry was prepared from the Si-Mg precipitates, an alkali hydroxide and water. Then the slurry was transferred into an autoclave and heated at $200{ }^{\circ} \mathrm{C}$ under autogenous water vapor for 3 h. The product that formed was filtered and dried at $80{ }^{\circ} \mathrm{C}$ for $15 \mathrm{~h}$. The chemical compositions of the smectite catalysts prepared were determined by an X-ray fluorescence method (Table 1). The smectites are designated as SM-Me, in which Me denotes the alkali metal incorporated into the sample. The samples of SM-Na were further numbered as SM-Na-1, SM-Na-2, etc. according to the order of the amount of Na atoms incorporated. 
Table 1

For comparison, MgO (Kishida Chemical Co.), 9.3 and 12.7 wt.\% $\mathrm{NaOH} / \mathrm{SiO}_{2}$ and 12.7 wt.\% $\mathrm{NaOH} / \mathrm{MgO}$ were used in a few experiments. The $\mathrm{NaOH}$ loaded catalysts were prepared by impregnation of either a porous silica gel (Aldrich Davisil grade 646) or MgO with aqueous solutions of $\mathrm{NaOH}$. The catalyst was dried at $110^{\circ} \mathrm{C}$ in air for $16 \mathrm{~h}$. The $\mathrm{NaOH}$ loadings of 9.3 and $12.7 \mathrm{wt} . \%$ are the same as those of SM-Na-2 and SM-Na-6, respectively, on the assumption that all sodium ions exist in the smectites in the form of $\mathrm{NaOH}$.

\subsection{Characterization of catalysts}

X-ray powder diffraction (XRD) patterns of the smectite samples prepared were recorded on a JEOL JDX-8030 diffractometer using nickel filtered $\mathrm{Cu}-\mathrm{K} \alpha$ radiation. The samples were scanned in the range of $2-70^{\circ}$ with a step of $0.02^{\circ}$. BET surface area and pore size distribution were obtained from nitrogen adsorption-desorption isotherms at $-196{ }^{\circ} \mathrm{C}$ with a Nova 1200 automatic physisorption instrument (Quantachrome Corporation). The samples were degassed at $100^{\circ} \mathrm{C}$ under vacuum for 30 min prior to the measurements.

Basic properties of the catalysts were measured by temperature programmed desorption (TPD) of adsorbed $\mathrm{CO}_{2}$ using a conventional flow reactor. After a stream of 20 vol.\% $\mathrm{CO}_{2}-\mathrm{He}$ mixture was passed over $0.2 \mathrm{~g}$ of a catalyst sample at room temperature for $20 \mathrm{~min}$, gases in the reactor were flushed with a helium stream. Then the temperature was ramped at a heating rate of $10 \mathrm{~K} / \mathrm{min}$ up to $900{ }^{\circ} \mathrm{C}$. The effluent from the reactor was analyzed by mass spectrometry.

\subsection{Catalytic reactions}

The transesterification of ethyl acetate with methanol was carried out in a $100 \mathrm{~cm}^{3}$ glass batch reactor attached with a water-cooled condenser. Ethyl acetate $(10 \mathrm{mmol})$, methanol $\left(5 \mathrm{~cm}^{3}\right)$ and the catalyst (31 mg) were charged in the reactor and then the reaction mixture was refluxed for $30 \mathrm{~min}$ at $70{ }^{\circ} \mathrm{C}$. After the reaction, the mixture was cooled by ice-water, separated from the solid catalyst by filtration and 
analyzed using a gas chromatograph with a flame ionization detector.

For the Knoevenagel condensation of benzaldehyde with ethyl cyanoacetate, the same glass reactor was employed. The reactor was charged with acetone $\left(8 \mathrm{~cm}^{3}\right)$, benzaldehyde $(9.9 \mathrm{mmol})$, ethyl cyanoacetate $(9.4 \mathrm{mmol})$ and the catalyst $(0.31 \mathrm{~g})$, and the reaction mixture was refluxed at $60{ }^{\circ} \mathrm{C}$ for $3 \mathrm{~h}$, followed by the same procedures as described above.

The one-pot synthesis of DMC from propylene oxide, $\mathrm{CO}_{2}$ and methanol was carried out in a 50 $\mathrm{cm}^{3}$ stainless steel high pressure reactor. The experimental setup used is shown elsewhere [27]. In a typical run, the reactor was charged with the catalyst $(0.5 \mathrm{~g})$, propylene oxide $(28.6 \mathrm{mmol})$ and methanol $\left(8 \mathrm{~cm}^{3}\right)$, purged with $\mathrm{CO}_{2}$ several times at atmospheric pressure, and heated up to $150{ }^{\circ} \mathrm{C}$. Then, liquid $\mathrm{CO}_{2}$ was further injected into the reactor up to $6 \mathrm{MPa}$ under stirring. The mixture was stirred for $1 \mathrm{~h}$ and then analyzed in the above-mentioned manners.

\section{Results and discussion}

\section{1. Catalyst characterization}

\subsubsection{Textural properties}

Figure 1 illustrates the XRD patterns of the smectite catalysts prepared. The typical peaks of smectite are observed at $2 \theta$ values of around 7, 20, 35 and 60 degrees (ASTM 9-31, 25-1385). The peaks of SM-Li are slightly sharper compared with those of the other smectites and are accompanied with several spikes, which are ascribable to the XRD peaks of lithium silicate, $\mathrm{Li}_{2} \mathrm{SiO}_{3}$ (ASTM 29-829).

Figure 1

Table 2 lists the BET surface areas, the total pore volumes and the average pore diameters of the smectite catalysts synthesized. Figure 2 shows the relationship between the BET surface area and the amount of alkali atoms for these samples. The BET surface area tends to decrease with the increasing amount of alkali atoms incorporated. The influence of the nature of the alkali atoms is insignificant. Similar 
to this, the total pore volume also tends to decrease with the content of alkali atoms, as shown in Fig. 3. On the other hand, the average pore diameter does not change with the content of alkali atoms except for SM-Li (Table 2). SM-Li has a larger average pore diameter. Figure 4 depicts the pore size distribution curves of the smectite catalysts. For either SM-Na or SM-K, a maximum appears at around $3.5 \mathrm{~nm}$, while a maximum is seen at $3.8 \mathrm{~nm}$ for SM-Li. When the content of sodium atoms is increased (SM-Na samples), the distribution curve becomes broader and the maximum peak height is decreased.

Table 2, Figure 2, Figure 3, Figure 4

Torii et al. previously explained the pore structure of synthesized smectites by a model of “smectite-intercalated smectite", in which small smectite fragments act as pillars between the layers $[7,8]$. The XRD peaks of SM-Li are slightly sharper than those of SM-Na and SM-K (Fig.1), indicating that the crystalline size of SM-Li is larger than those of SM-Na and SM-K. So, the sizes of the pillars in SM-Li should probably be longer, resulting in the larger pore size. A similar pillar model can explain the dependence of the BET surface and the total pore volume of the present SM-Na samples on the amount of sodium atoms incorporated. For the construction of the smectite-intercalated smectite structure, electrostatic repulsion between the smectite fragments is an important factor; as the Na content is increased, the repulsion should become weakened (shielded) and this would cause more close packing/stacking of the fragments, resulting in the decrease in the BET surface area. On the other hand, another factor is also significant for the pore volume. The sodium metals seem to be in the form of hydroxide and sodium hydroxide particles would be packed between the layers of smectite structure. So, SM-Na catalysts containing larger amounts of sodium atoms have smaller total pore volumes.

\subsubsection{Basic properties}

The smectite catalysts synthesized were examined by TPD of adsorbed $\mathrm{CO}_{2}$. Figure 5 shows the TPD spectra obtained. All the SM-Na catalysts show $\mathrm{CO}_{2}$ desorption peaks around $100{ }^{\circ} \mathrm{C}$ and $250{ }^{\circ} \mathrm{C}$. With increasing Na content, the intensity of the peak at $250{ }^{\circ} \mathrm{C}$ increases and tends to level off at larger Ni contents. In addition to these two peaks, three peaks appear above $600{ }^{\circ} \mathrm{C}$ over SM-Na samples containing large amounts of $\mathrm{Na}$ and they grow with its content. $\mathrm{CO}_{2}$ TPD spectra obtained with SM-K and SM-Li are 
slightly different from those over SM-Na. SM-K and SM-Li show only one broad peak above $600^{\circ} \mathrm{C}$ and the latter catalyst also shows a peak at $480{ }^{\circ} \mathrm{C}$, which is not observed over the other catalysts. Thus, the peak intensity and temperature are different among the catalysts, meaning that the strength and the number of basic sites vary with the composition of the catalysts. The peak at $100{ }^{\circ} \mathrm{C}$ is assigned to the desorption of $\mathrm{CO}_{2}$ physisorbed or adsorbed on weakly basic sites. Although conclusive definition is difficult at present, the peaks seen between 200 and $600{ }^{\circ} \mathrm{C}$ are tentatively assigned to the desorption of $\mathrm{CO}_{2}$ adsorbed on moderately basic sites, while the peaks above $600{ }^{\circ} \mathrm{C}$ are assigned to that of $\mathrm{CO}_{2}$ adsorbed on strongly basic sites. Figure 6 plots the amounts of these three basic sites against the content of sodium atoms. The amount of weakly basic sites shows a maximum at a sodium content of 1.8 atoms per a unit cell, but the difference due to the sodium content is small. On the other hand, the amounts of moderately and strongly basic sites vary in wider ranges with the sodium content than the weakly basic sites. The amount of moderately basic sites levels off at a sodium content of 1.8 atoms per a unit cell, and from this content level, the amount of strongly basic site starts to increase appreciably. The structures of basic sites have not been given at the present stage and will be discussed afterward.

Figure 5

Figure 6

Figure 7 depicts a $\mathrm{CO}_{2}$ TPD profile of $\mathrm{NaOH} / \mathrm{SiO}_{2}$ containing $\mathrm{NaOH}$ in the same quantity $(12.7$ wt.\%) as with SM-Na-6. Over $\mathrm{NaOH} / \mathrm{SiO}_{2}$, two peaks of $\mathrm{CO}_{2}$ ascribable to the desorption of $\mathrm{CO}_{2}$ adsorbed on weakly and moderately basic sites are observed at slightly higher temperatures compared with the SM-Na catalysts. Above $600{ }^{\circ} \mathrm{C}$, one broad peak at $680{ }^{\circ} \mathrm{C}$ is seen along with two sharp ones at 740 and $760^{\circ} \mathrm{C}$. There is no desorption around $800{ }^{\circ} \mathrm{C}$ where a strong peak appears over SM-Na-6. In the same way as for the cases of the smectite catalysts, the amounts of weakly, moderately and strongly basic sites were estimated from the TPD profile and these numbers were 28.6, 20.3 and 12.6\% of those over SM-Na-6, respectively. Despite the same $\mathrm{NaOH}$ loading, $\mathrm{NaOH} / \mathrm{SiO}_{2}$ has smaller amounts of basic sites. Simple impregnation of $\mathrm{NaOH}$ on silica is not efficient to generate basic sites.

Figure 7 


\subsection{Catalytic performance}

\subsubsection{Transesterification of ethyl acetate with methanol}

Transesterification of ester with alcohol is one of the important reactions for the synthesis of fine chemicals and it can be catalyzed by bases. Transesterification of ethyl acetate with methanol was carried out to investigate the properties of the smectite samples as base catalysts. Figure 8 plots the yield of methyl acetate (MA) against the amount of alkali atoms incorporated. The MA yield increases with the content of alkali atoms. As shown above, the numbers of basic sites increase with the content of alkali atoms. So, the relationship between the catalytic activity observed and the number of basic sites estimated from the peak area in the TPD runs was examined. The activity is correlated well with the amount of moderately basic sites, as shown in Fig. 9. No good correlation was seen with the amounts of either weakly or strongly basic sites or with the total amount of basic sites. In Fig. 9, the MA yield obtained with $12.7 \mathrm{wt} . \% \mathrm{NaOH} / \mathrm{SiO}_{2}$ is also plotted as a closed circle against the amount of moderately basic sites over the catalyst. This catalyst has nearly the same amount of moderately basic sites as SM-Na-1 and gives a similar yield to that over SM-Na-1. These findings strongly suggest that the moderately basic sites present on the smectite catalysts are responsible for the transesterification reaction. A similar conclusion was previously drawn for the transesterification of ethylene carbonate and methanol to produce DMC and ethylene glycol $[24,27,28]$, which is relevant to the one-pot synthesis of DMC described below.

Figure 8, Figure 9

\subsubsection{Knoevenagel reaction of benzaldehyde and ethyl cyanoacetate}

Konoevenagel condensation is one of $\mathrm{C}-\mathrm{C}$ bond forming reactions and is widely used for the synthesis of valuable chemicals. The smectite catalysts were also employed for the Knoevenagel condensation of benzaldehyde and ethyl cyanoacetate to ethyl cyanocinnamate (ECC). Figure 10 shows the relationship between the ECC yield and the amount of alkali atoms incorporated. The differences in the yield for different contents of alkali atoms are not substantial. The yields obtained with S-K and S-Li are respectively higher and lower than those of S-Na catalysts; however, the differences among the catalysts 
are marginal. For comparison, pure $\mathrm{SiO}_{2}$ (Davisil 646) and 9.3 and 12.7 wt.\% $\mathrm{NaOH} / \mathrm{SiO}_{2}$ catalysts were employed for the reaction under the same conditions. The pure silica gave a very low ECC yield of $7.2 \%$. On the other hand, $\mathrm{NaOH} / \mathrm{SiO}_{2}$ catalysts gave the ECC yields comparable to those of the smectite catalysts and the yield did not depend on the loading of $\mathrm{NaOH}$, similar to Fig. 10. The ECC yields obtained with 9.3 and 12.7 wt. $\% \mathrm{NaOH} / \mathrm{SiO}_{2}$ catalysts were 64.6 and $67.0 \%$, respectively.

Figure 10

Climent et al. carried out the Knoevenagel reactions of benzaldehyde with malononitrile, ethyl cyanoacetate and diethyl malonate by using three different solid base catalysts [29]. Based on the reaction results and the order of acidity of the molecules containing active methylenic groups, they concluded that moderately basic sites are responsible for the reaction of benzaldehyde and ethyl cyanoacetate. Although we examined the relationship of the ECC yield with the amount of a single group of weakly, moderately or strongly basic sites and with the amount of combined groups of two or three of these sites of different strength, no good correlation was found. The reason why the catalytic activity for Knoevenagel condensation depends little on the content of alkali atoms is not clear at present (Fig. 10). However, one possible explanation is given here. As shown above, the increase in the amount of alkali atoms incorporated enhances the basicity of smectite, which can raise the activity of smectite; on the other hand, it reduces the BET surface area and the total pore volume, which can lower the activity. These opposite effects of the alkali incorporation may result in the independence of the Knoevenagel condensation activity regarding the content of alkali atoms.

For comparison, the Knoevenagel reaction was also carried out with MgO. The ECC yield obtained was $44.9 \%$. The activity of $\mathrm{MgO}$ for the reaction is lower than those of the present smectite catalysts. Corma et al. reported the same Knoevenagel condensation using alkali-exchanged zeolites and showed that the alkaline $\mathrm{X}$ zeolites have several times higher activities than the alkaline Y zeolites [30]. Although the reaction conditions they employed were very different from those in the present study, according to the kinetic parameters that they determined over the zeolites, the alkaline $\mathrm{X}$ zeolites should give the ECC yields of about 75\% under the conditions employed in the present study. Thus, the activities of the alkaline $\mathrm{X}$ zeolites are comparable with the present smectite catalysts. 


\subsubsection{One-pot synthesis of DMC from propylene oxide, $\mathrm{CO}_{2}$ and methanol}

The last base-catalyzed reaction examined is the one-pot synthesis of dimethyl carbonate (DMC) from propylene oxide (PO), $\mathrm{CO}_{2}$ and methanol, which is one of the reactions for chemical fixation of $\mathrm{CO}_{2}$. This reaction is the integration of two reactions, $\mathrm{CO}_{2}$ cycloaddition to $\mathrm{PO}$, producing propylene carbonate (PC), and transesterification of PC with methanol to produce DMC and propylene glycol (PG) (Scheme 2). If it proceeds effectively, preliminary synthesis and separation of cyclic carbonate can be avoided, leading to more economical processes for the DMC synthesis from $\mathrm{CO}_{2}$. So, several research groups including ours have recently studied this reaction extensively $[25,27,31-37]$. When the smectite catalysts were used for the one-pot reaction, DMC and PG were formed along with the intermediate of PC. In addition to these products, however, 1-methoxy-2-propanol (1-MP) and 2-methoxy-1-propanol (2-MP) were produced as by-products via the methanolysis of PO (Scheme 3). The product distribution was observed to change by the composition of smectite catalysts.

Scheme 2, Scheme 3

Figure 11 plots the yields of DMC and PC against the content of alkali atoms. The yield of DMC increases with the content of alkali atoms except SM-Li, which gives a lower DMC yield than expected from its alkali content. The same tendency was also observed for the formation of PG (not shown in Fig. 11). The yield of PC does not depend on the alkali amount so much. In contrast to the DMC formation, the yields of 1-MP and 2-MP tend to decrease with increasing amounts of alkali atoms (Fig. 12). The exception was again SM-Li. Similar to the cases of the other reactions, the relationships between the DMC yield and the amounts of basic sites were examined. Figure 13 shows that the DMC yield is well correlated with the sum of the amounts of moderately and strongly basic sites, suggesting that these basic sites are responsible for the one-pot synthesis.

Figure 11, Figure 12, Figure 13

Table 3 compares the catalytic performance of the one-pot reaction and the amounts of moderately and strongly basic sites among 12.7 wt.\% $\mathrm{NaOH} / \mathrm{SiO}_{2}$, SM-Na-1 and SM-Na-6. NaOH/SiO${ }_{2}$ 
gives almost the same DMC yield with SM-Na-1, while the former catalyst gives slightly smaller 1-MP and 2-MP yields. This suggests again that moderately and strongly basic sites are responsible for the one-pot synthesis, because the total amounts of the basic sites over these catalysts are comparable. It is also seen that this $\mathrm{NaOH} / \mathrm{SiO}_{2}$ catalyst is much less effective for the reaction than SM-Na-6 in spite of the same $\mathrm{NaOH}$ loading because of lower amounts of basic sites.

Table 3

The one-pot reaction was carried out for various periods of reaction time using SM-Na-6. For comparison, similar experiments were also conducted for the transesterification of PC and methanol in the presence of dense $\mathrm{CO}_{2}$ (Scheme 2b). Figure 14 illustrates the variations of the DMC yield with time for both reactions. The DMC yield of the one-pot reaction increases for the initial $5 \mathrm{~h}$, but the yield remains unchanged after $5 \mathrm{~h}$. A similar trend of the DMC yield is observed for the transesterification, but the yield does not change after a shorter period of $2 \mathrm{~h}$. When these reactions were carried out with the doubled amount of the catalyst for $5 \mathrm{~h}$, the DMC yields were not different from those in Fig. 14. It has been reported that the transesterification of ethylene carbonate with methanol to produce DMC and ethylene glycol is a reversible reaction and hence limited by thermodynamic equilibrium [25]. This limitation would also occur in the transesterification of PC and methanol. So, it can be concluded that the DMC yield of the one-pot reaction, which involves the transesterification step, is also limited by the equilibrium.

Figure 14

Figure 14 also shows that the time to reach to the constant DMC yield is different for different reactions. The time for the transesterification of PC ( $2 \mathrm{~h})$ is shorter than that for the one-pot reaction $(5 \mathrm{~h})$, suggesting that the transesterification reaches to its equilibrium faster than the one-pot reaction. In separate runs, the cycloaddition of $\mathrm{CO}_{2}$ to $\mathrm{PO}$ was carried out at the same substrate/catalyst ratio but in the absence of methanol. When the reaction was carried out for $1 \mathrm{~h}$, the yield of PC observed (4 \%) was much lower than that in the total yield of PC and DMC in the one-pot reaction (36 \%). On the basis of these results, it can be concluded that the $\mathrm{CO}_{2}$ cycloaddition to $\mathrm{PO}$ is the rate-determining step for the one-pot reaction. $\mathrm{Li}$ 
et al. [36] conducted the same one-pot reaction by using a $\mathrm{KOH}$ loaded molecular sieve and proposed that the step of the $\mathrm{CO}_{2}$ addition was promoted by methanol. Similar promotional effects of methanol may also exist in the present catalyst system.

Previously, it was suggested that both moderately and strongly basic sites are active for the $\mathrm{CO}_{2}$ cycloaddition to PO and that the latter are more effective than the former [23,27]. On the other hand, moderately basic sites of solid base catalysts were suggested to be active sites for the transesterification of cyclic carbonate with methanol $[23,27,28]$. This is coincident with the present results of the transesterification between ethyl acetate and methanol described in the foregoing section. As discussed above, the step of $\mathrm{CO}_{2}$ cycloaddition should be the rate-determining step for the one-pot reaction. So, the DMC yield of the one-pot reaction depends on the sum of the amounts of moderately and strongly basic sites, as indicated by Fig. 13.

Hattori et al. previously reported that alcoholysis of PO was catalyzed by both solid acid and base catalysts [38]. It was also shown that synthetic smectites may have both acidic and basic sites [14,15]. So, one can assume that, when the content of alkali atoms in smectite was increased, its acid sites were deactivated by alkali hydroxide, which could result in the lower yields of 1-MP and 2-MP. However, this is excluded because Hattori et al. also showed that base and acid catalysts gave different product distribution patterns for alcoholysis [38]. The base catalyst produces a larger amount of 1-alkoxy-2-propanol, while the solid acid catalyst gives a larger amount of 2-alkoxy-1-propanol. As shown in Fig. 12, the yield of 1-MP is always higher than that of 2-MP and the ratio of 1-MP/2-MP is practically constant, strongly suggesting that the methanolysis of PO proceeds over the basic sites of synthetic smectites examined. Probably, more strongly basic sites should be more selective for the one-pot reaction than for the methanolysis, resulting in the lower yields of 1-MP and 2-MP over the smectites having larger amounts of strongly basic sites.

As shown above, the DMC yield with the present smectite catalysts is not so high because of the reaction equilibrium and the side reaction of methanolysis. Particularly, the side reaction is the serious problem to be resolved. Jiang and Yang [33] have reported that a $\mathrm{K}_{2} \mathrm{CO}_{3}-\mathrm{KCl}$ loaded $\mathrm{MgO}$ catalyst is selective for the one-pot reaction. The selectivity for the methanolysis observed with this catalyst was below 7\%. On the other hand, we reported that pure MgO gave the methanolysis selectivity of 52\% [27]. These results suggest that using a combination of alkali hydroxide and other alkali salts for the smectite synthesis may make the smectite catalysts more efficient. To obtain such catalysts, further experiments are 
still required.

\subsection{Feachures of basic sites}

As illustrated in Fig. 5, SM-Na catalysts show five $\mathrm{CO}_{2}$ TPD peaks around 100, 250, 670, 730 and $800{ }^{\circ} \mathrm{C}$. For convenience, the first, the second and the other three peaks are assigned to the desorption peaks of $\mathrm{CO}_{2}$ adsorbed on weakly, moderately and strongly basic sites, respectively. The amounts of these three basic sites change by the content of Na atoms in different modes, as shown in Fig. 6. The amount of weakly basic sites depends less on the Na content compared with the moderately and strongly basic sites. Furthermore, in $\mathrm{CO}_{2}$ TPD profiles over pure silica and pure $\mathrm{MgO}, \mathrm{CO}_{2}$ desorption peaks around $100{ }^{\circ} \mathrm{C}$ were also observed. The weakly basic sites may be the surfaces of the smectite layer that are free from alkali atoms. Figure 15 depicts a $\mathrm{CO}_{2}$ TPD profiles of 12.7 wt.\% NaOH/MgO. A large amount of $\mathrm{CO}_{2}$ evolution occurs above $600{ }^{\circ} \mathrm{C}$ over this sample and it still increases at temperatures up to $900{ }^{\circ} \mathrm{C}$. This strongly suggests that there is some interaction between $\mathrm{NaOH}$ and $\mathrm{MgO}$, since no desorption of $\mathrm{CO}_{2}$ was observed above $600{ }^{\circ} \mathrm{C}$ over pure $\mathrm{MgO}$ [27]. Probably, there should be a similar interaction between $\mathrm{NaOH}$ and $\mathrm{SiO}_{2}$ over $\mathrm{NaOH} / \mathrm{SiO}_{2}$, resulting in the desorption peaks above $600{ }^{\circ} \mathrm{C}$ over this catalyst (Fig. 7). Thus, it can be concluded that the strongly basic sites of the smectite catalysts involve alkali hydroxide particles interacting with the layers of the smectites. On the other hand, the amount of moderately basic sites levels off at a sodium content of 1.8 atoms per a unit cell, where the amount of strongly basic site starts to increase appreciably (Fig. 6). This suggests that the Na atoms involved in the moderately basic sites exist in a different form from those in the strongly basic sites. Although the conclusive definition is difficult at the present stage, the moderately basic sites may involve $\mathrm{NaOH}$ particles not interacting at all with the layers of the smectites or interacting with them less strongly.

Figure 15

Incorporation of lithium into smectite is less effective than sodium and potassium for the catalytic activity for the one-pot synthesis. SM-Li shows no $\mathrm{CO}_{2}$ desorption peak above $700{ }^{\circ} \mathrm{C}$, where two or one desorption peak are/is observed over SM-Na and SM-K. The interaction of lithium atoms discussed above may be weaker than those of sodium and potassium. In addition, lithium atoms are exchangeable with the 
metal cations occupying the octahedral sites [14]. Furthermore, SM-Li showed the XRD peaks assigned to lithium silicate (Fig. 1). Thus, lithium atoms in these forms may be inactive for the reaction.

As shown above the present smectite catalysts may be used for other base catalyzed reactions. The activity may further been improved by optimizing preparation conditions and using different metal cations to be incorporated. Changes in the preparation conditions would modify their textural properties, which in turn would change their catalytic performance. Also, incorporation of different metal cations in the octahedral sheet and/or the interlayer could cause enhancement in their catalytic performance. Those aspects have not been studied in detail for the alkali incorporated smectite catalysts, which are open for further work.

\section{Conclusions}

In the present study, a series of mesoporous smectites incorporated with alkali hydroxides has been prepared. The incorporation induces the reduction in the surface area and the total pore volume; however, it enhances the amount and strength of basic sites, resulting in higher catalytic activity for the selected model reactions. The reaction results, in combination with the results of $\mathrm{CO}_{2} \mathrm{TPD}$, reveal that the activity for the transesterification is mostly determined by the amount of moderately basic sites, while that for the one-pot synthesis of DMC is determined by the total amount of both moderately and strongly basic sites. The side-reaction of the one-pot synthesis, methanolysis of the epoxide, can be retarded by increasing the content of alkali atoms. The activity for the Knoevenagel reaction depends little on the content of alkali atoms. The present results demonstrate that the smectite catalysts that incorporate alkali metal cations would be applicable to other base-catalyzed reactions and the activity may be tuned by changing the catalyst composition.

\section{Acknowledgement}

The authors express their sincere thanks to Dr. M. Shirai and Dr. K. Torii (AIST) for kindly 
supplying us the smectite samples used in the present study.

\section{References}

[1] H. Hattori, Chem. Rev. 95 (1995) 537-558.

[2] K. Tanabe, W. Hölderich, Appl. Catal. A: Gen. 181 (1999) 399-434.

[3] H. Hattori, Appl. Catal. A: Gen. 222 (2001) 247-259.

[4] R. J. Davis, J. Catal. 216 (2003) 396-405.

[5] Y. Ono, J. Catal. 216 (2003) 406-415.

[6] K. Torii, T. Iwasaki, Chem. Lett. (1988) 2045-2048.

[7] K. Torii, T. Iwasaki, Y. Onodera, M. Shimada, Nippon Kagaku Kaishi (1989) 345-351.

[8] K. Torii, T. Iwasaki, Y. Onodera, T. Nishiyama, J. Ceram. Soc. Jpn. 100 (1992) 368-372.

[9] K. Torii, Y. Onodera, T. Iwasaki, M. Shirai, M. Arai, Y. Nishiyama, J. Porous Mater. 4 (1997) 261-268.

[10] M. Shirai, K. Aoki, T. Miura, K. Torii, M. Arai, Chem. Lett. (2000) 36-37.

[11] C. T. Kresge, M. E. Leonowicz, W. J. Roth, J. C. Vartuli, J. S. Beck, Nature 359 (1992) 710-712.

[12] T. Yanagisawa, T. Shimizu, K. Kuroda, Bull. Chem. Soc. Jpn. 63 (1990) 1535-1537.

[13] S. Inagaki, Y. Fukushima, K. Kuroda, J. Chem. Soc. Chem. Commun. (1993) 680-681.

[14] E. Suzuki, S. Idemura, Y. Ono, Appl. Clay. Sci. 3 (1988) 123-134.

[15] Y. Nishiyama, M. Arai, S.-L. Guo, N. Sonehara, T. Naito, K. Torii, Appl. Catal. A: Gen. 95 (1993) $171-181$.

[16] M. Arai, M. Kanno, Y. Nishiyama, K. Torii, M. Shirai, J. Catal. 182 (1999) 507-510.

[17] M. Arai, Y. Minato, K. Torii, M. Shirai, Catal. Lett. 61 (1999) 83-87.

[18] M. Shirai, K. Aoki, K. Torii, M. Arai, Appl. Catal. A: Gen. 187 (1999) 141-146.

[19] M. Shirai, K. Aoki, Y. Minato, K. Torii, M. Arai, Stud. Surf. Sci. Catal. 129 (2000) 435-442.

[20] M. Arai, S.-L. Guo, M. Shirai, Y. Nishiyama, K. Torii, J. Catal. 161 (1996) 704-712.

[21] M. Shirai, K. Torii, M. Arai, Stud. Surf. Sci. Catal. 130 (2000) 2105-2110.

[22] K. Torii, T. Iwasaki, Clay Sci. 7 (1987) 1-16. 
[23] S. Fujita, B. M. Bhanage, Y. Ikushima, M. Shirai, K. Torii, M. Arai, Catal. Lett. 79 (2002) 95-98.

[24] B. M. Bhanage, S. Fujita, Y. He, Y. Ikushima, M. Shirai, K. Torii, M. Arai, Catal. Lett. 83 (2002) $137-141$

[25] B. M. Bhanage, S. Fujita, Y. Ikushima, K. Torii, M. Arai, Green Chem. 5 (2003) 71-75.

[26] K. Torii, T. Iwasaki, Catal. Lett. (1986) 2021-2024.

[27] B. M. Bhanage, S. Fujita, Y. Ikushima, M. Arai, Appl. Catal. A: Gen. 219 (2001) 259-266.

[28] M. Kirishiki, Y. Onda, T. Tsuneki, Shokubai (Catal. Cata.) 38 (1996) 92-92.

[29] M. J. Climent, A. Corma, S. Iborra, A. Velty, J. Mol. Catal. A: Chem. 182-183 (2002) 327-342.

[30] A. Corma, V. Fornes, R. M. Martin-Aranda, H. Garcia, J. Primo, Appl. Catal. 59 (1990) 237-248.

[31] H. Zhu, L.-B. Chen, Y.-Y. Jiang, Polym. Adv. Tech. 7 (1996) 701-703.

[32] H. Cui, T. Wang, F. Wang, C. Gu, P. Wang, Y. Dai, Ind. Eng. Chem. Res. 42 (2003) 3865-3870.

[33] Q. Jiang, Y. Yang, Catal. Lett. 95 (2004) 127-133.

[34] Y. Chang, T. Jiang, B. Han, Z. Liu, W. Wu, L. Gao, J. Li, H. Gao, G. Zhao, J. Huang, Appl. Catal. A: Gen. 263 (2004) 179-186.

[35] Y. Kishimoto, I. Ogawa, Ind. Eng. Chem. Res. 43 (2004) 8155-8162.

[36] Y. Li, X. Zhao, Y. Wang, Appl. Catal. A: Gen. 279 (2005) 205-208.

[37] J.-S. Tian, J.-Q. Wang, J.-Y. Chen, J.-G. Fan, F. Cai, L.-N. He, Appl. Catal. A: Gen. 301 (2006) $215-221$.

[38] H. Hattori, M. Shima, H. Kabashima, Stud. Surf. Sci. Catal. 130 (2000) 3507-3512. 
Table 1 Composition of smectite catalysts prepared

\begin{tabular}{|c|c|c|c|c|c|c|}
\hline \multicolumn{2}{|c|}{ Catalyst } & \multicolumn{5}{|c|}{ Number of atoms per unit cell } \\
\hline & & $\mathrm{Si}$ & $\mathrm{Mg}$ & $\mathrm{Na}$ & $\mathrm{K}$ & $\mathrm{Li}$ \\
\hline (a) & SM-Na-1 & 8.0 & 5.67 & 0.84 & 0 & 0 \\
\hline (b) & SM-Na-2 & 8.0 & 5.88 & 1.51 & 0 & 0 \\
\hline (c) & SM-Na-3 & 8.0 & 5.89 & 1.80 & 0 & 0 \\
\hline (d) & SM-Na-4 & 8.0 & 6.09 & 2.25 & 0 & 0 \\
\hline (e) & SM-Na-5 & 8.0 & 6.13 & 2.45 & 0 & 0 \\
\hline (f) & SM-Na-6 & 8.0 & 6.82 & 2.64 & 0 & 0 \\
\hline (g) & SM-K & 8.0 & 6.09 & 0.47 & 1.7 & 0 \\
\hline (h) & SM-Li & 8.0 & 5.41 & 0.47 & 0 & 2.56 \\
\hline
\end{tabular}


Table 2 Textural properties of smectite catalysts prepared

\begin{tabular}{|c|c|c|c|c|}
\hline \multicolumn{2}{|c|}{ Catalyst } & \multirow{2}{*}{$\begin{array}{c}\mathrm{S}_{\mathrm{BET}}\left(\mathrm{m}^{2} / \mathrm{g}\right) \\
695\end{array}$} & \multirow{2}{*}{$\begin{array}{c}\mathrm{V}_{\text {pore }}\left(\mathrm{cm}^{3} / \mathrm{g}\right) \\
0.440\end{array}$} & \multirow{2}{*}{$\begin{array}{c}\mathrm{d}_{\mathrm{av}}(\mathrm{nm}) \\
2.53\end{array}$} \\
\hline (a) & SM-Na-1 & & & \\
\hline (b) & SM-Na-2 & 392 & 0.242 & 2.46 \\
\hline (c) & SM-Na-3 & 379 & 0.233 & 2.46 \\
\hline (d) & SM-Na-4 & 173 & 0.107 & 2.47 \\
\hline (e) & SM-Na-5 & 200 & 0.124 & 2.48 \\
\hline (f) & SM-Na-6 & 107 & 0.067 & 2.52 \\
\hline (g) & SM-K & 190 & 0.126 & 2.65 \\
\hline (h) & SM-Li & 118 & 0.124 & 4.22 \\
\hline
\end{tabular}

${ }^{\mathrm{a}} \mathrm{S}_{\mathrm{BET}}, \mathrm{V}_{\text {pore }}$ and $\mathrm{d}_{\mathrm{av}}$ denote BET surface area, total pore volume and average pore diameter, respectively. 
Table 3 The one-pot synthesis of DMC and the amounts of moderately and strongly basic sites over 12.7 wt.\% $\mathrm{NaOH} / \mathrm{SiO}_{2}$ and SM-Na catalysts.

\begin{tabular}{|c|c|c|c|c|c|c|}
\hline \multirow[t]{2}{*}{ Catalyst } & \multicolumn{4}{|c|}{ Yield (\%) } & \multicolumn{2}{|c|}{ Amount of sites $(\mu \mathrm{mol} / \mathrm{g})$} \\
\hline & DMC & $\mathrm{PC}$ & 1-MP & 2-MP & Moderate base & Strong base \\
\hline $\mathrm{NaOH} / \mathrm{SiO}_{2}$ & 9 & 15 & 39 & 20 & 40 & 28 \\
\hline SM-Na-1 & 8 & 13 & 42 & 25 & 37 & 9 \\
\hline SM-Na-6 & 24 & 18 & 26 & 13 & 199 & 223 \\
\hline
\end{tabular}


Captions for schemes and figures

Scheme 1. Base-catalyzed model reactions studied: (a) transesterification of ethyl acetate with methanol, (b) Knoevenagel condensation of benzaldehyde with ethyl cyanoacetate and (c) the one-pot synthesis of dimethyl carbonate from propylene oxide, carbon dioxide and methanol.

Scheme 2. Two reactions involved in the one-pot synthesis of DMC: (a) Cycloaddition of $\mathrm{CO}_{2}$ to propylene oxide and (b) Transesterification of propylene carbonate with methanol.

Scheme 3. Methanolysis of propylene oxide.

Fig. 1. XRD patterns of smectite samples synthesized. (a) SM-Na-1; (b) SM-Na-2; (c) SM-Na-3; (d) Sm-Na-4; (e) SM-Na-5; (f) SM-Na-6; (g) SM-K; (h) SM-Li.

Fig. 2. Relationship between BET surface area and the quantity of alkali atoms incorporated for smectite samples synthesized.

Fig. 3. Relationship between the total pore volume and the quantity of alkali atoms incorporated for smectite samples synthesized.

Fig. 4. Pore size distribution curves of smectite samples synthesized. The letters denote the same samples as given in Tables 1 and 2 and Fig. 1.

Fig. 5. $\mathrm{CO}_{2}$ TPD profiles over smectite samples synthesized. The letters denote the same samples as given in Tables 1 and 2 and Fig. 1.

Fig. 6. Changes of the amounts of basic sites with the content of sodium. ( $\square$ ) weakly, ( $\bigcirc$ ) moderately and ( $)$ strongly basic sites 
Fig. 7. $\mathrm{CO}_{2}$ TPD profile over 12.7 wt. $\% \mathrm{NaOH} / \mathrm{SiO}_{2}$.

Fig. 8. Influence of the amount of alkali atoms incorporated on the activity of smectite catalysts for the transesterification of ethyl acetate with methanol. Reaction conditions: catalyst, $31 \mathrm{mg}$; ethyl acetate, 10 mmol; methanol, $5 \mathrm{~cm}^{3}$; temperature, $70{ }^{\circ} \mathrm{C}$; time, $30 \mathrm{~min}$.

Fig. 9. Relationship between the transesterification activity and the amount of moderately basic sites for the smectite samples synthesized and 12.7 wt.\% NaOH/SiO${ }_{2}$. ( $\bigcirc$ ), SM-Na; ( $\square$ ), SM-K; ( $\square$ ), SM-Li; ( $)$ ), $\mathrm{NaOH} / \mathrm{SiO}_{2}$.

Fig. 10. Influence of the amount of alkali atoms incorporated on the activity of smectite catalysts prepared for Knoevenagel condensation of benzaldehyde and ethyl cyanoacetate. Reaction conditions: catalyst, 310 mg; benzaldehyde, $9.9 \mathrm{mmol}$; ethyl cyanoacetate, $9.4 \mathrm{mmol}$; acetone, $8 \mathrm{~cm}^{3}$; temperature, $60{ }^{\circ} \mathrm{C}$; time, $3 \mathrm{~h}$.

Fig. 11. Influence of the amount of alkali atoms incorporated on the yields of DMC and PC in the one-pot DMC synthesis. Circle, square and lozenge symbols represent the DMC and PC yields obtained with SM-Na, SM-K and SM-Li, respectively. Reaction conditions: catalyst, 0.5 g; propylene oxide, 28.6 mmol; methanol, $8 \mathrm{~cm}^{3}$; $\mathrm{CO}_{2}, 6 \mathrm{MPa}$; temperature, $150{ }^{\circ} \mathrm{C}$; time, $1 \mathrm{~h}$.

Fig. 12. Influence of the amount of alkali atoms incorporated on the yields of 1-MP and 2-MP in the one-pot DMC synthesis. Circle, square and lozenge symbols represent the 1-MP and 2-MP yields obtained with SM-Na, SM-K and SM-Li, respectively. The reaction conditions are the same as those given for Fig. 11.

Fig. 13. Relationship between the DMC yield and the amounts of moderately and strongly basic sites. Circle, square and lozenge symbols represent the DMC yields obtained with SM-Na, SM-K and SM-Li, respectively. The reaction conditions are the same as those given for Fig. 11. 
Fig. 14. Variations of the DMC yield with time for the one-pot synthesis of DMC $(O)$ and the transesterification of PC with methanol ( $)$. Reaction conditions: SM-Na-6, 0.5 g; propylene oxide, 28.6; propylene carbonate, $28.6 \mathrm{mmol}$; methanol, $8 \mathrm{~cm}^{3}$; $\mathrm{CO}_{2}$, $8 \mathrm{MPa}$; temperature, $150{ }^{\circ} \mathrm{C}$.

Fig. 15. $\mathrm{CO}_{2}$ TPD profile over 12.7 wt. $\% \mathrm{NaOH} / \mathrm{MgO}$. 
(a)

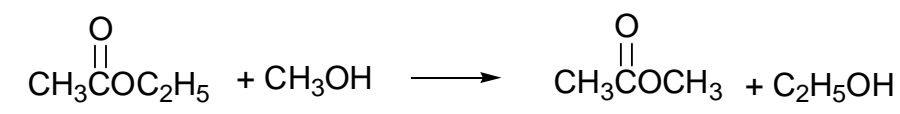

(b)

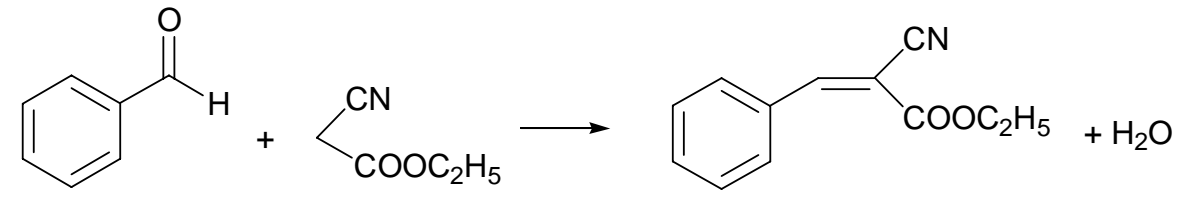

(c)<smiles>CC1O[C@@H]1C(=O)O</smiles><smiles>COC(=O)[OH+]C(C)O</smiles>

Scheme 1. Base-catalyzed model reactions studied. (a) transesterification of ethyl acetate with methanol, (b) Knoevenagel condensation of benzaldehyde with ethyl cyanoacetate and (c) the one-pot synthesis of dimethyl carbonate from propylene oxide, carbon dioxide and methanol. 
(a)<smiles>CC1CO1</smiles><smiles>CC1COC(=O)O1</smiles>

(b)<smiles>CC1COC(=O)O1</smiles><smiles>COC(=O)OC</smiles>

DMC<smiles>CC(O)CO</smiles>

Scheme 2. Two reactions involved in the one-pot synthesis of DMC. (a) Cycloaddition of $\mathrm{CO}_{2}$ to propylene oxide. (b) Transesterification of propylene carbonate with methanol. 


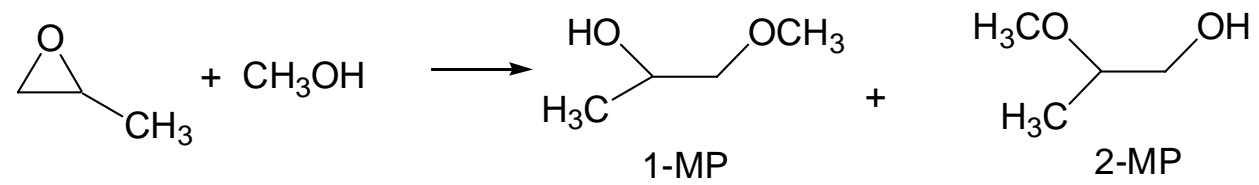

Scheme 3. Methanolysis of propylene oxide. 


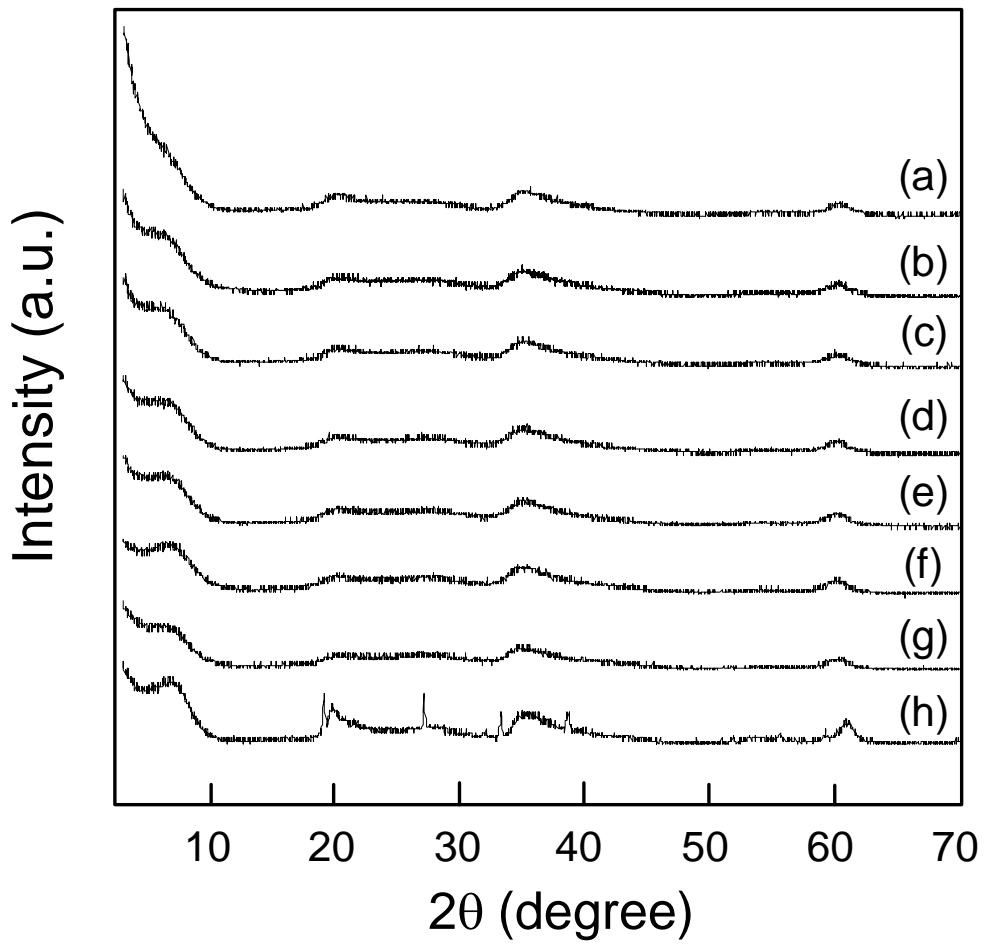

Fig. 1. XRD patterns of smectite samples synthesized. (a) SM-Na-1; (b) SM-Na-2; (c) SM-Na-3; (d) Sm-Na-4; (e) SM-Na-5; (f) SM-Na-6; (g) SM-K; (h) SM-Li. 


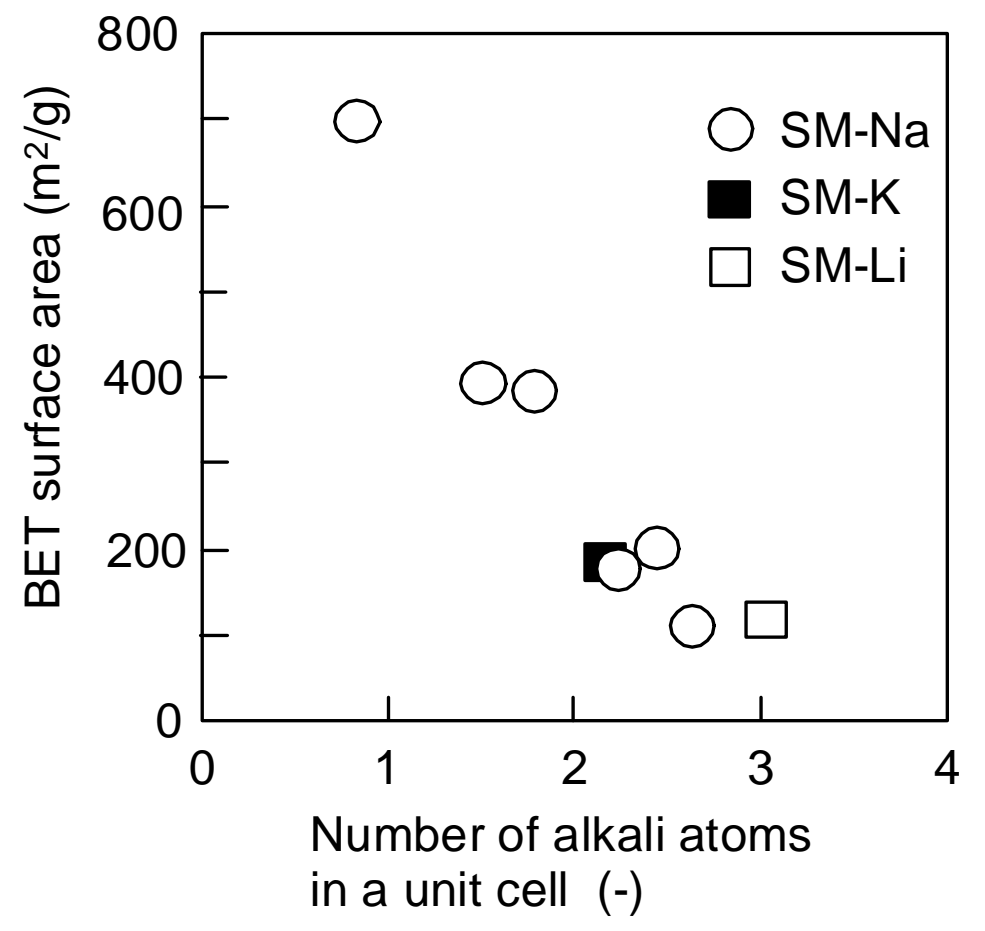

Fig. 2. Relationship between BET surface area and the quantity of alkali atoms incorporated for smectite samples synthesized. 


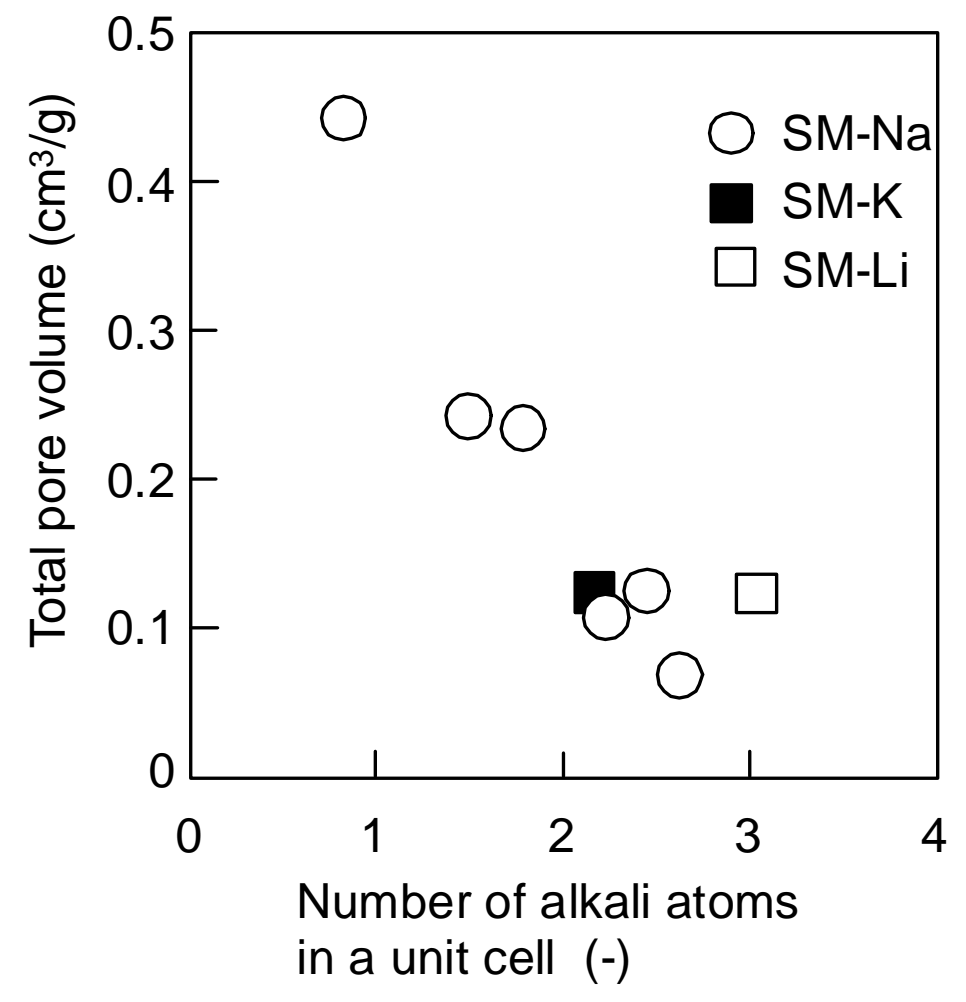

Fig. 3. Relationship between the total pore volume and the quantity of alkali atoms incorporated for smectite samples synthesized. 


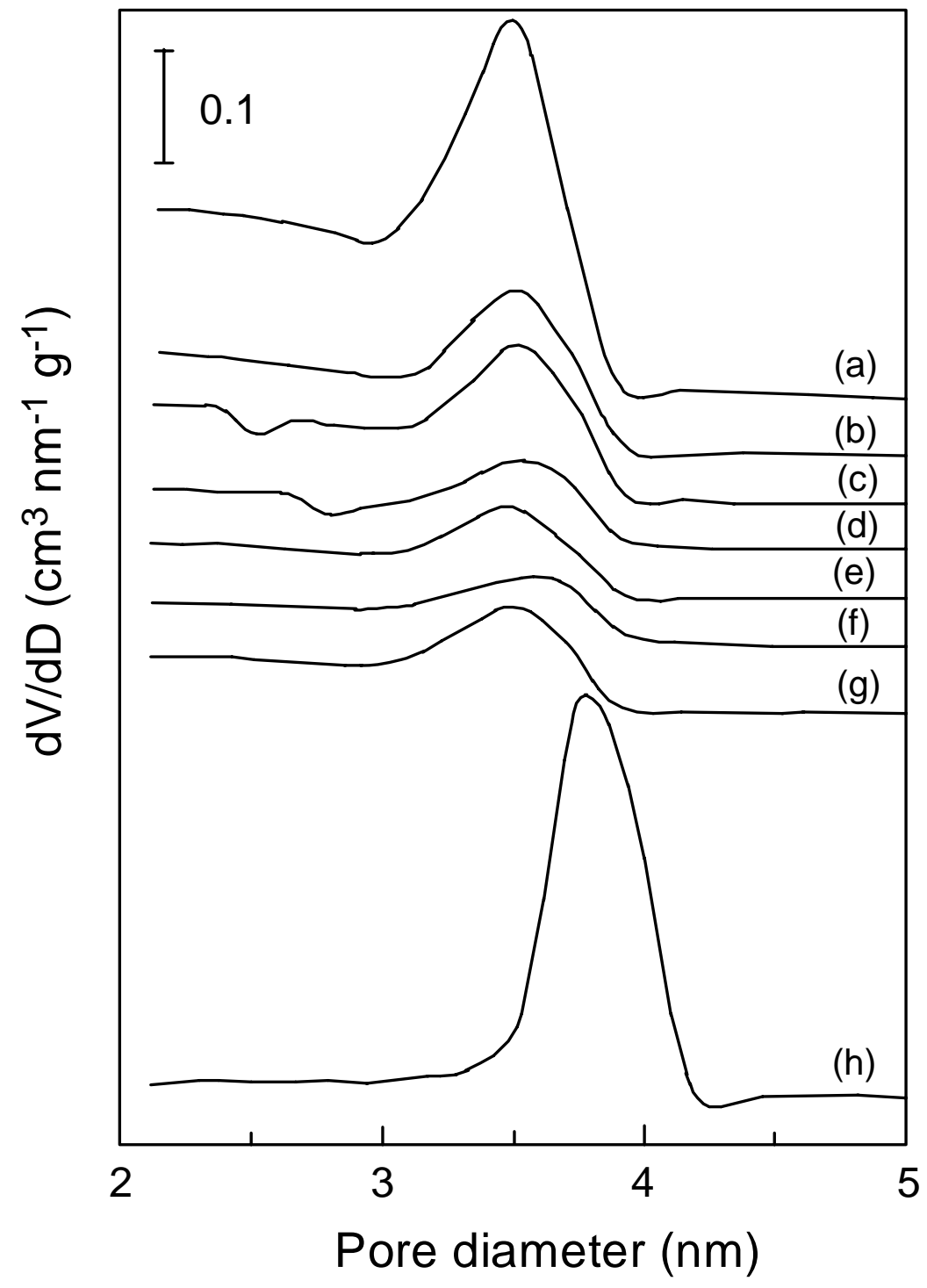

Fig. 4. Pore size distribution curves of smectite samples synthesized. The alphabets denote the same samples as given in Tables 1 and 2 and Fig. 1. 


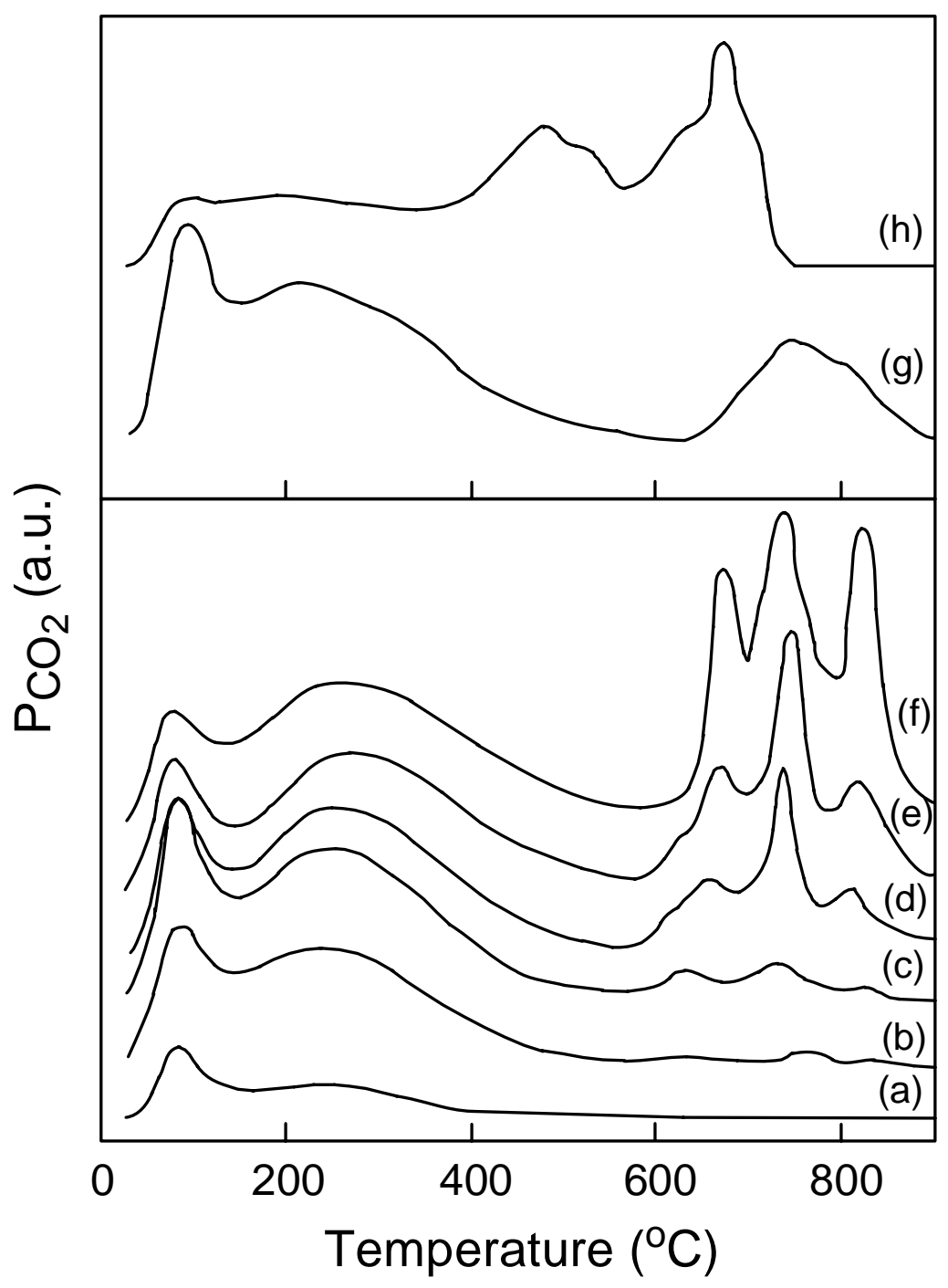

Fig. 5. $\mathrm{CO}_{2}$ TPD profiles over smectite samples synthesized. The alphabets denote the same samples as given in Tables 1 and 2 and Fig. 1. 


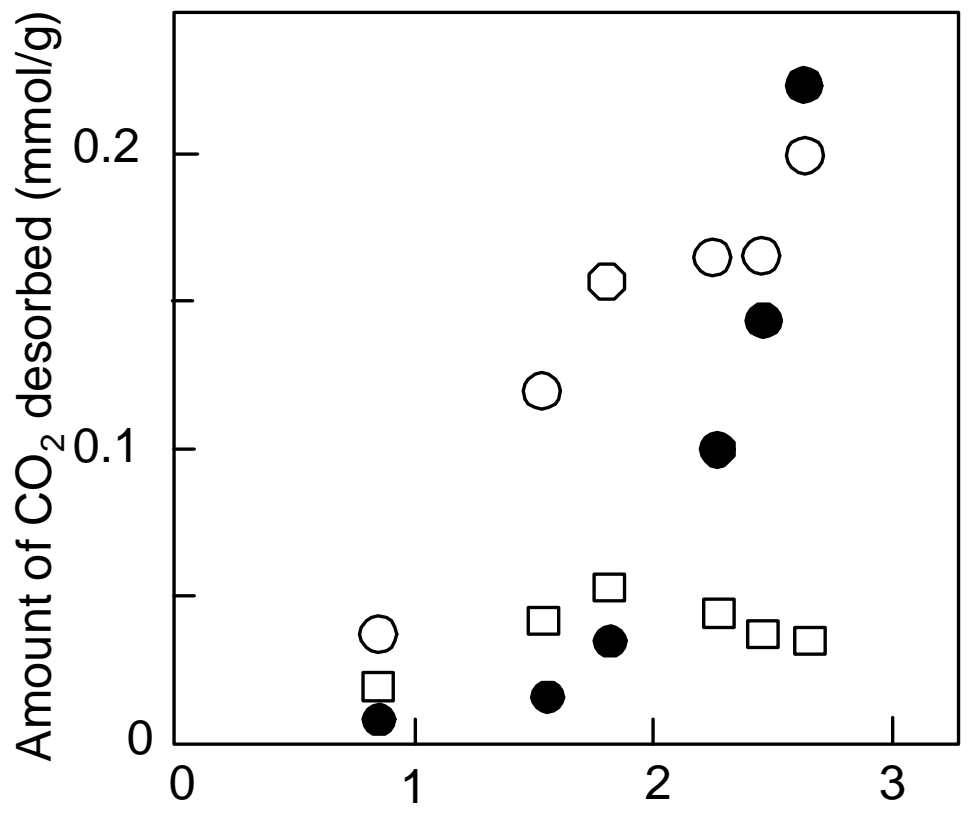

Number of $\mathrm{Na}$ atoms in a unit cell [-]

Fig. 6. Changes of the amounts of basic sites with the content of sodium. ( $\square$ ) weakly, ( $\bigcirc$ ) moderately and ( $(\bigcirc)$ strongly basic sites 


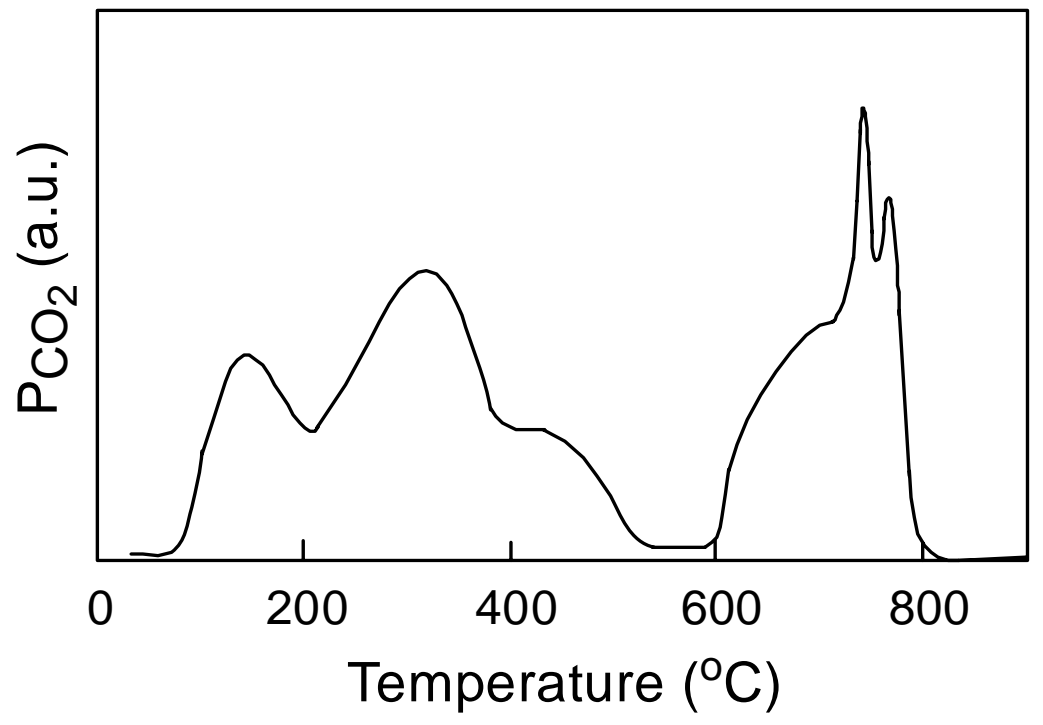

Fig. 7. $\mathrm{CO}_{2} \mathrm{TPD}$ profile over 12.7 wt. $\% \mathrm{NaOH} / \mathrm{SiO}_{2}$. 


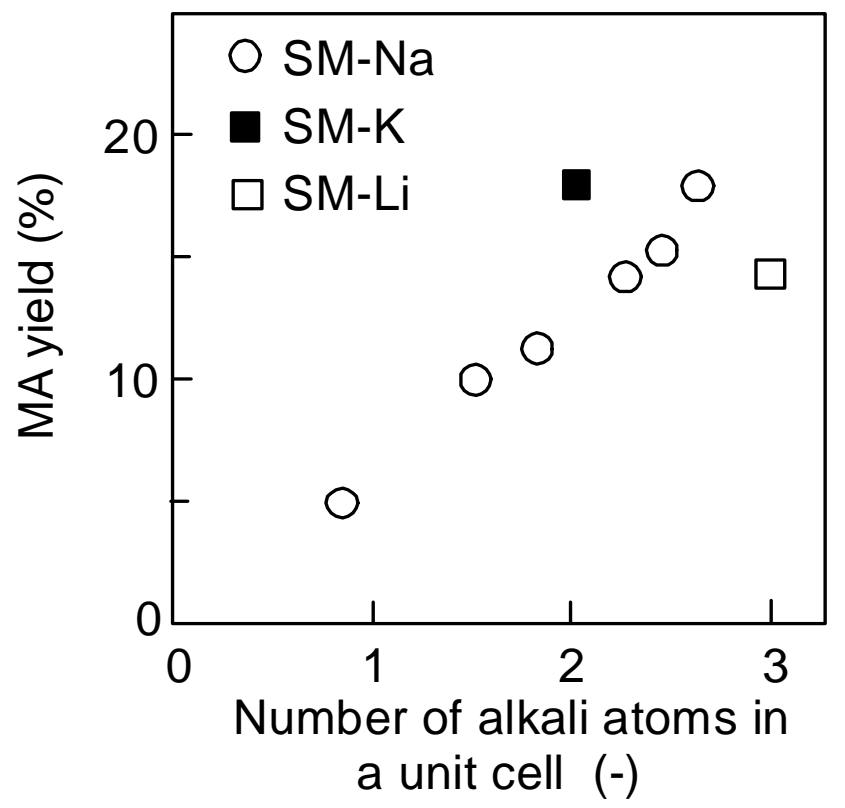

Fig. 8. Influence of the amount of alkali atoms incorporated on the activity of smectite catalysts for the transesterification of ethyl acetate with methanol. Reaction conditions: catalyst, $31 \mathrm{mg}$; ethyl acetate, 10 mmol; methanol, $5 \mathrm{~cm}^{3}$; temperature, $70^{\circ} \mathrm{C}$; time, $30 \mathrm{~min}$. 


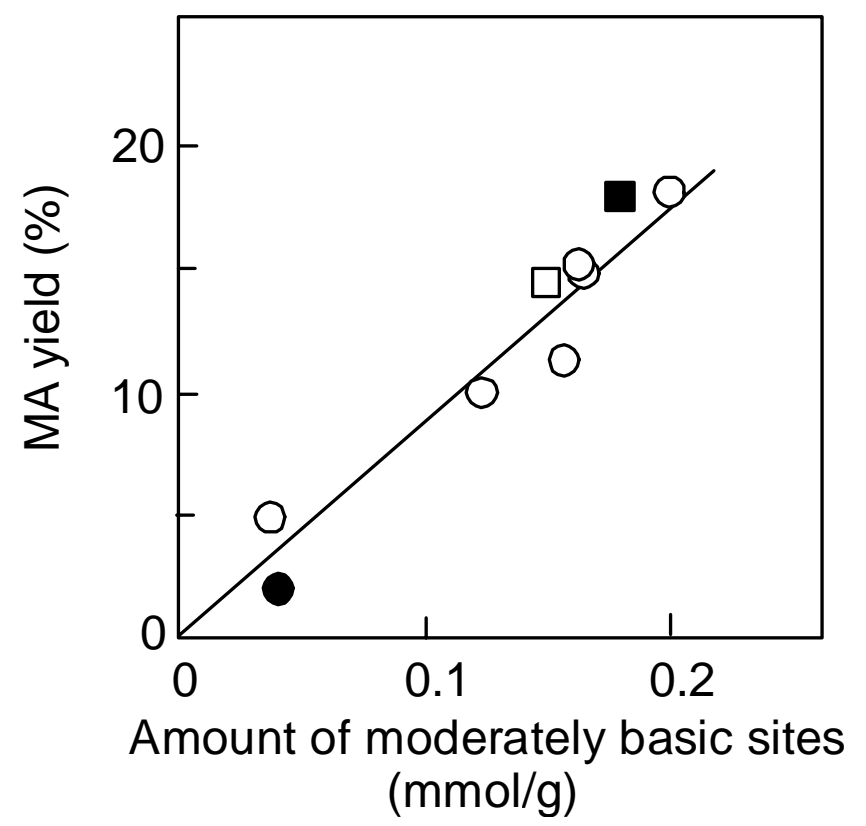

Fig. 9. Relationship between the transesterification activity and the amount of moderately basic sites for the smectite samples synthesized and 12.7 wt.\% NaOH/SiO.$(\bigcirc)$ ), SM-Na; ( $\square$ ), SM-K; ( $\square$ ), SM-Li; ( $\bigcirc$ ), $\mathrm{NaOH} / \mathrm{SiO}_{2}$. 


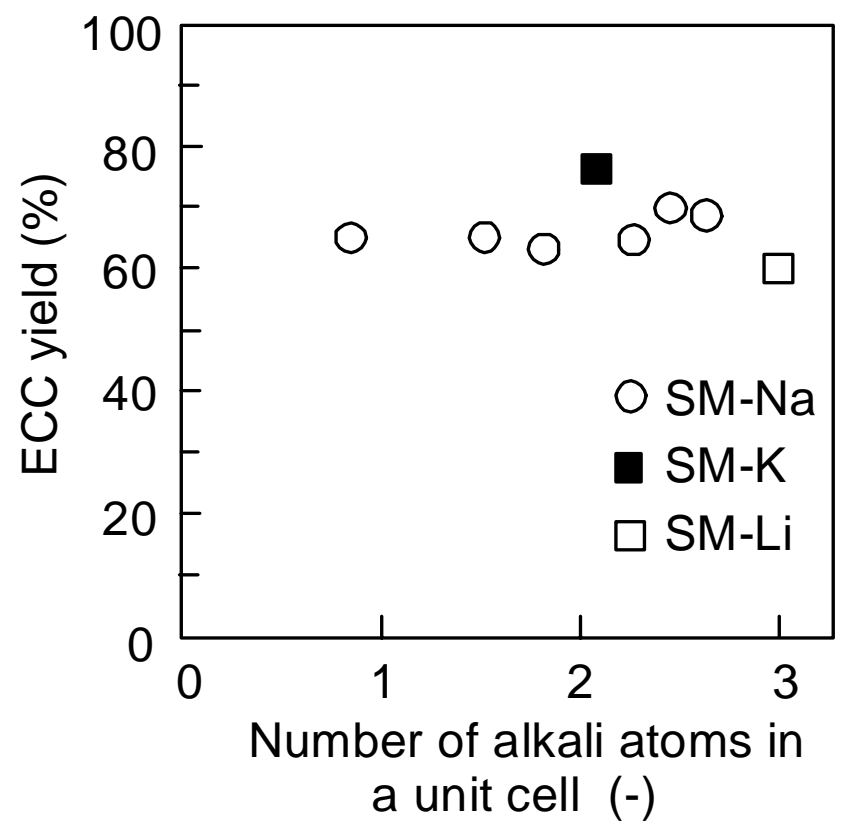

Fig. 10. Influence of the amount of alkali atoms incorporated on the activity of smectite catalysts prepared for Knoevenagel condensation of benzaldehyde and ethyl cyanoacetate. Reaction conditions: catalyst, 310 mg; benzaldehyde, $9.9 \mathrm{mmol}$; ethyl cyanoacetate, $9.4 \mathrm{mmol}$; acetone, $8 \mathrm{~cm}^{3}$; temperature, $60{ }^{\circ} \mathrm{C}$; time, $3 \mathrm{~h}$. 


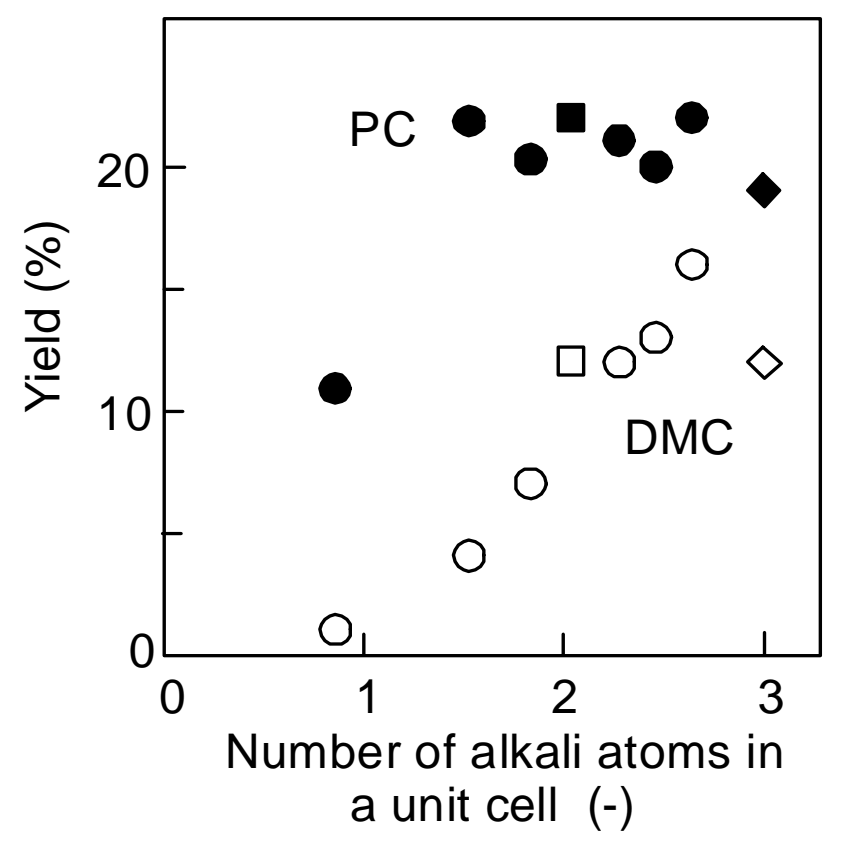

Fig. 11. Influence of the amount of alkali atoms incorporated on the yields of DMC and PC in the one-pot DMC synthesis. Circle, square and lozenge symbols represent the DMC and PC yields obtained with SM-Na, SM-K and SM-Li, respectively. Reaction conditions: catalyst, 0.5 g; propylene oxide, 28.6 mmol; methanol, $8 \mathrm{~cm}^{3}$; $\mathrm{CO}_{2}, 6 \mathrm{MPa}$; temperature, $150^{\circ} \mathrm{C}$; time, $1 \mathrm{~h}$. 


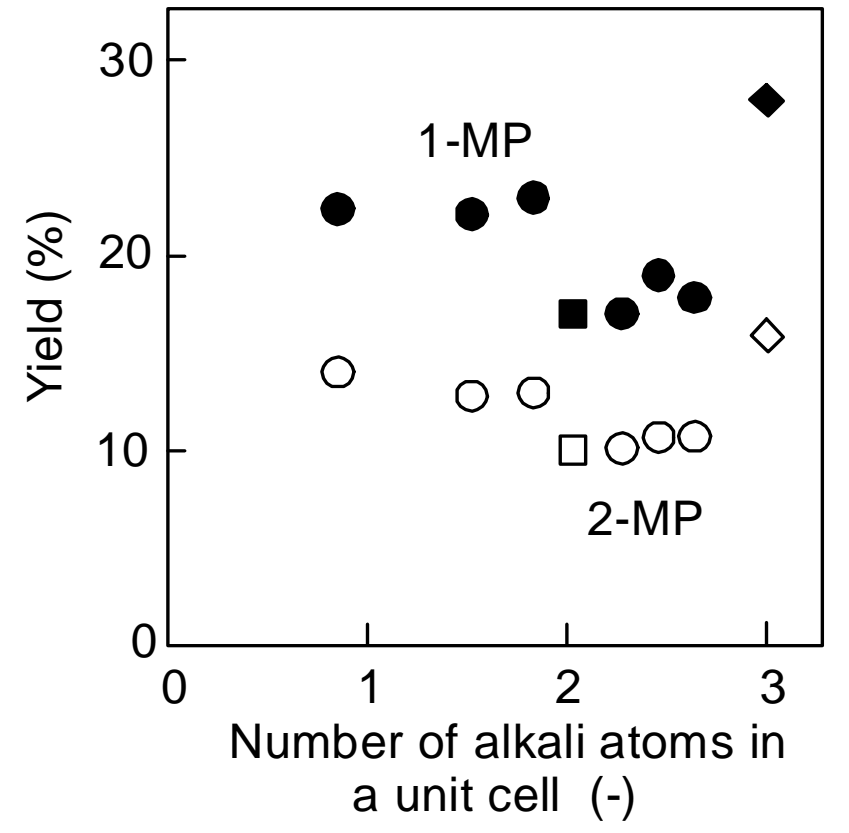

Fig. 12. Influence of the amount of alkali atoms incorporated on the yields of 1-MP and 2-MP in the one-pot DMC synthesis. Circle, square and lozenge symbols represent the 1-MP and 2-MP yields obtained with SM-Na, SM-K and SM-Li, respectively. The reaction conditions were the same as given for Fig. 11. 


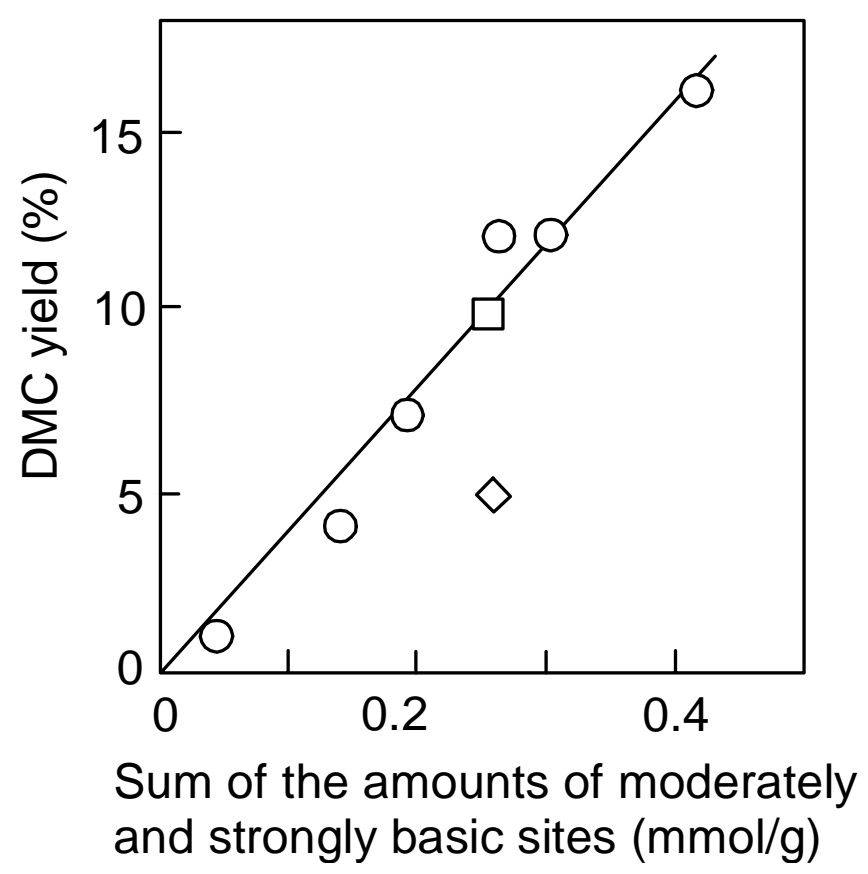

Fig. 13. Relationship between the DMC yield and the amounts of moderately and strongly basic sites. Circle, square and lozenge symbols represent the DMC yields obtained with SM-Na, SM-K and SM-Li, respectively. The reaction conditions were the same as given for Fig. 11. 


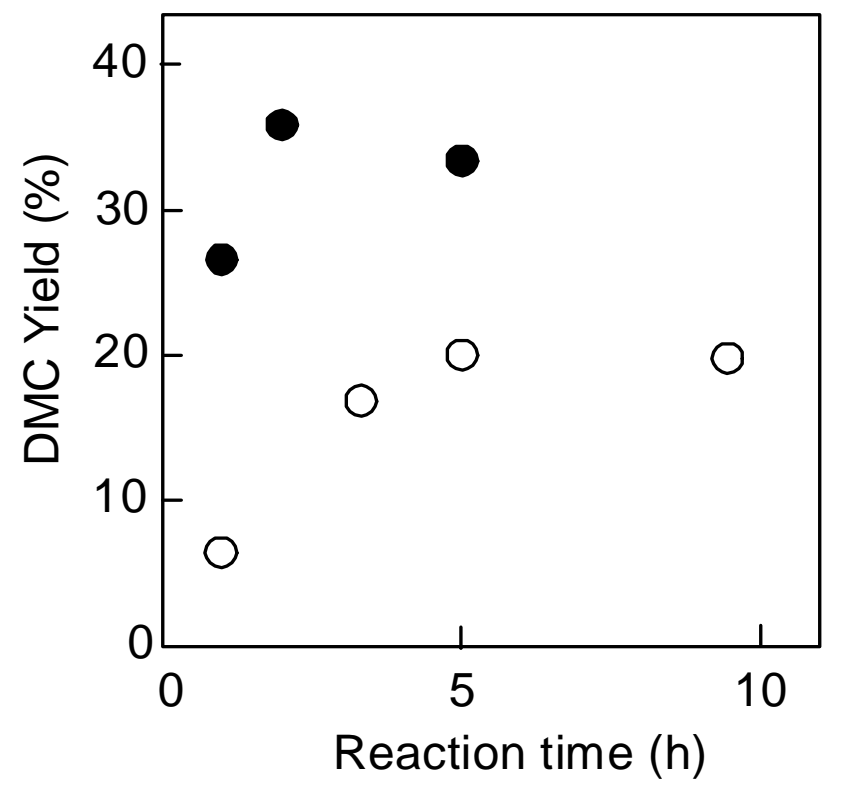

Fig. 14. Variations of the DMC yield with time for the one-pot synthesis of DMC ( $\bigcirc)$ and the transesterification of PC with methanol ( ) Reaction conditions: SM-Na-6, 0.5 g; propylene oxide, 28.6; propylene carbonate, $28.6 \mathrm{mmol}$; methanol, $8 \mathrm{~cm}^{3}$; $\mathrm{CO}_{2}$, $8 \mathrm{MPa}$; temperature, $150^{\circ} \mathrm{C}$. 


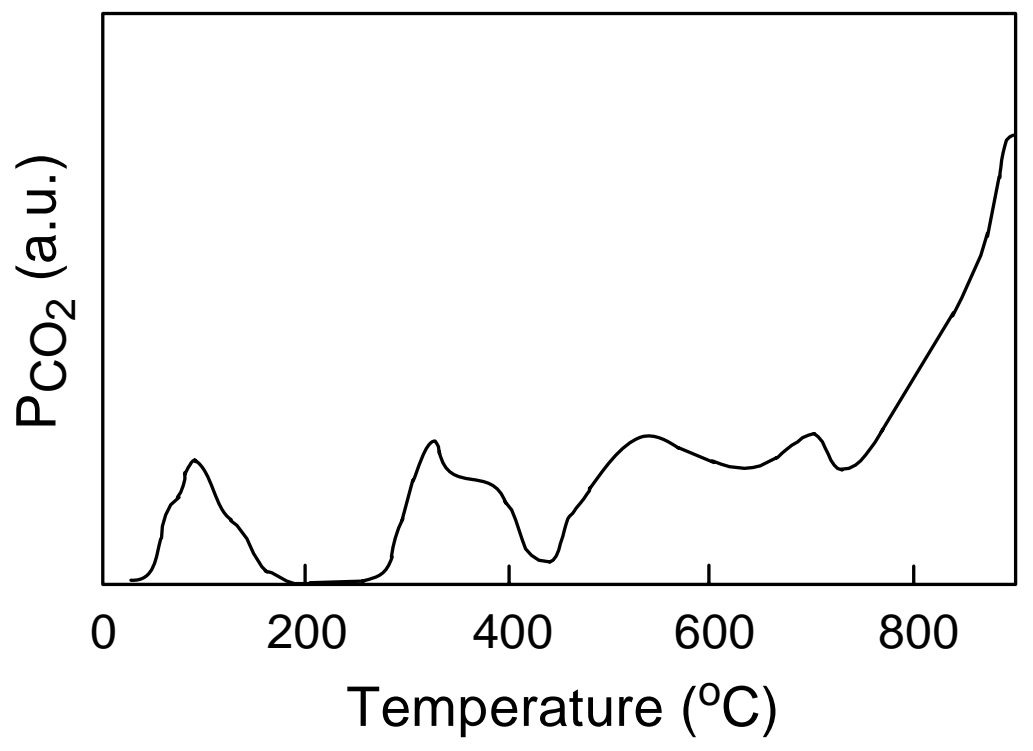

Fig. 15. $\mathrm{CO}_{2}$ TPD profile over 12.7 wt.\% NaOH/MgO. 